\title{
GEOGRAPHIC INFORMATION SYSTEM IN EPIDEMIOLOGICAL STUDY: CANCERS OF THE RESPIRATORY SYSTEM KONYA
}

\author{
Hatice Canan GUNGOR $^{1 *}$, Gülgün ÖZKAN ${ }^{2}$ \\ ${ }^{1 *}$ Necmettin Erbakan University, Meram Vocational School, Department of Civil Defense \\ and Firefighting, Konya, Turkey; \\ ${ }^{2}$ Konya Technical University Faculty of Engıneering sand Natural Sclences Map Engineerıng, Konya, Turkey; \\ "Corrosponding Author Hatice Canan GUNGOR, e-mail: cgungor@erbakan.edu.tr; gozkan@ktun.edu.tr;
}

Received June 2021; Accepted July 2021; Published August 2021;

DOI: https://doi.org/10.31407/ijees11.417

\begin{abstract}
In this study, Konya province was chosen as the location with its 31 district border. Among the environmental factors of soil-water-air pollution, which is epidemiologically accepted as one of the causes of respiratory system cancer, soil pollution was evaluated and its relationship with the disease was investigated. The relationship between space and disease was analyzed on thematic maps created with Geographic Information Systems (GIS) software. GIS is an advanced technology that enables to match information with space, to visualize and keep information up to date.Soil pollution is defined by the Nickel values found in the soil. Disease data were obtained from the address data of the patients who were included in the respiratory system (Lung, Larynx, Nasopharynx) of cancer patients diagnosed between 2005 and 2009, obtained from the Konya Provincial Health Directorate.Of the 1302 cases registered in 31 districts, $84.18 \%$ were male cancer cases and $15.82 \%$ were female cancer cases. When the average age is examined, it is understood that the disease often progresses between the ages of 60-69. In the western and southwestern parts of the province, it was observed that respiratory system cancers overlapped with high pollution points. In this study, the effect of the living area on respiratory system cancers was confirmed, and the importance of improving regional characteristics was emphasized.
\end{abstract}

Keywords: GIS, Epidemiology, Respiratory Cancers, Soil Pollution, Environment and Disease. 